OPEN ACCESS

Edited by:

Lorenzo Lastrucci,

University of Florence, Italy

Reviewed by:

Adriano Stinca,

Università degli Studi della Campania

Luigi Vanvitelli, Italy

Jacques Haury,

Agrocampus Ouest, France

*Correspondence:

Viktor R. Tóth

toth.viktor@okologia.mta.hu

Paolo Villa

villa.p@irea.cnr.it

Specialty section:

This article was submitted to

Functional Plant Ecology,

a section of the journal

Frontiers in Plant Science

Received: 20 December 2018

Accepted: 29 April 2019

Published: 16 May 2019

Citation:

Tóth VR, Villa P, Pinardi M and

Bresciani M (2019) Aspects

of Invasiveness of Ludwigia and Nelumbo in Shallow Temperate

Fluvial Lakes.

Front. Plant Sci. 10:647.

doi: 10.3389/fpls.2019.00647

\section{Aspects of Invasiveness of Ludwigia and Nelumbo in Shallow Temperate Fluvial Lakes}

\author{
Viktor R. Tóth ${ }^{1 *}$, Paolo Villa ${ }^{2 *}$, Monica Pinardi ${ }^{2}$ and Mariano Bresciani ${ }^{2}$ \\ ${ }^{1}$ Balaton Limnological Institute, MTA Centre for Ecological Research, Hungarian Academy of Sciences, Tihany, Hungary, \\ ${ }^{2}$ Institute for Electromagnetic Sensing of the Environment, National Research Council, Milan, Italy
}

The relationship between invasive plant functional traits and their invasiveness is still the subject of scientific investigation, and the backgrounds of transition from non-native to invasive species in ecosystems are therefore poorly understood. Furthermore, our current knowledge on species invasiveness is heavily biased toward terrestrial species; we know much less about the influence of allochthonous plant traits on their invasiveness in aquatic ecosystems. In this paper, we present the results of a study on physiological and ecological traits of two introduced and three native macrophyte species in the Mantua lakes system (northern Italy). We compared their photophysiology, pigment content, leaf reflectance, and phenology in order to assess how the invasive Nelumbo nucifera and Ludwigia hexapetala perform compared to native species, Nuphar lutea, Nymphaea alba, and Trapa natans. We found $L$. hexapetala to have higher photosynthetic efficiency and to tolerate higher light intensities than N. nucifera and the native species especially at extreme weather conditions (prolonged exposure to high light and higher temperatures). Chlorophyll $a$ and $b$, and carotenoids content of both allochthonous species were substantially higher than those of native plants, suggesting adaptive response to the ecosystem of Mantua lakes system. Higher variability of recorded data in invasive species was also observed. These observations suggest advanced photosynthetic efficiency of the invasive species, especially $L$. hexapetala, resulting in faster growth rates and higher productivity. This was supported by the evaluation of seasonal dynamics mapped from satellite remote sensing data. This study provides empirical evidence for the relationship between specific plant physiological traits and invasiveness of aquatic plant species, highlighting the importance of trait studies in predicting ecosystem-level impacts of invasive plant species.

Keywords: macrophytes, photophysiology, leaf reflectance, leaf pigments, phenology, Trapa, Nuphar, Nymphaea

\section{INTRODUCTION}

Introduced species pose an imminent threat to biodiversity, species composition and structure, as well as general functioning of their new ecosystems (Vitousek, 1990; D'Antonio and Kark, 2002; Vilà et al., 2011). This is especially the case in aquatic environments and for aquatic plants (Gallardo et al., 2016). Invasive species are responsible for displacing large numbers of native species throughout the world (Musil, 1993; Meyer and Florence, 1996; Holmes and Cowling, 1997). 
Although the introduction of species to new environments can result from natural processes, the vast majority in recent decades has occurred as either a direct (i.e., purposeful transport) or indirect (i.e., without human awareness) consequence of the anthropogenic collapse of biogeographic barriers (McKinney and Lockwood, 1999). In addition, anthropogenic pressure on ecosystems (e.g., altered land-use patterns, changes in climate regimes, increase in atmospheric $\mathrm{CO}_{2}$ ), and especially on aquatic ecosystems, foster favorable conditions for the establishment of introduced species (Dukes and Mooney, 1999; Hussner et al., 2014; Fasoli et al., 2018).

Multiple differences between native and alien species have been observed, and can be summarized as being associated with either more efficient resource use by the invasive plants (Vitousek, 1986; Baruch and Goldstein, 1999), or with invasive species' lack of natural enemies in their new habitats (Callaway and Aschehoug, 2000; Mitchell and Power, 2003). In general, from one side the invasive plants could outperform their native counterparts due to their higher phenotypic variability or phenological plasticity, i.e., the introduced plants are able to better acclimate and find unoccupied spatial and temporal niches where they can prevail (Pyšek and Richardson, 2007; Davidson et al., 2011). The higher phenological plasticity of an alien plant, reflecting into its seasonal dynamics, could affect its invasive success, since the possibility of extending its lifecycle beyond the lifecycles of native species can determine its ability to capture and utilize resources (Wolkovich and Cleland, 2011). From the other side, species could be successful in their new environment in the absence of enemies, pathogens or predators, from their former habitats, consequently freeing vital resources for production and development of the introduced species (Keane and Crawley, 2002; Colautti et al., 2004). Despite the advantages the introduced species have, this does not always correspond to biomass dominance; indeed, the background processes of how these advantages are translated into better performance in their new environments are still not fully understood (Davis et al., 2001; Funk and Vitousek, 2007). Moreover, in invasive plants sometimes even the certain disadvantages (for example in C assimilation) are converted into higher production and fitness (Hussner and Jahns, 2015). Even though invasive plants seem to have higher plasticity and enhanced functional traits in many instances (Pyšek and Richardson, 2007; Davidson et al., 2011), scientific literature still has to reach consensus as to whether the carbon acquisition and distribution of native and invasive plants differ across groups and ecosystems (Daehler, 2003; Van Kleunen et al., 2010; Leffler et al., 2014; Hussner and Jahns, 2015).

Within this context, macrophytes (i.e., aquatic plants) emerge as particularly interesting targets, for several reasons. Macrophytes tend to display higher diversity in temperate areas (Alahuhta et al., 2017), where human impacts are stronger, to show highly cosmopolitan features (Zhou and Zhou, 2009), and to occupy the extremes of the global spectrum of vegetation forms (Díaz et al., 2016). As such, macrophytes are more sensitive to ecosystem degradation and invasion processes, but also provide insight into the functional adaptation potential of plants to environmental conditions different from those of their native range.
The main aim of this study was to investigate and compare selected traits (physiological, spectral, and phenological) of two invasive floating-emergent aquatic plants and native macrophyte species found in a shallow temperate freshwater system. Toward this, we hypothesized that: (i) photophysiological performance (i.e., chlorophyll fluorescence, related to $\mathrm{C}$ acquisition) of invasive species is superior to that of native plants; (ii) leaf pigment pools of invasive plants are different in size and composition from native ones; (iii) photophysiological performance and pigment content show higher plasticity in invasive than in native species; (iv) invasive macrophytes can effectively exploit temporal niches left unoccupied by the seasonal dynamics of native species; and that (v) leaf spectroscopy can provide information about physiological traits of both invasive and native macrophytes.

\section{MATERIALS AND METHODS}

\section{Study Sites}

The Mantua lakes system (Laghi di Mantova), consisting of the Superior, Middle, and Inferior lakes, are three shallow (mean depth: $3.5 \mathrm{~m}$ ) fluvial lakes adjacent to the city of Mantua, Italy (Figure 1). The lakes are surrounded by urban areas, both residential and industrial, and the upstream basin is characterized by intensive agriculture. The Mantua lakes system is therefore exposed to diffuse sources of nutrients $(\mathrm{N}$ and $\mathrm{P}$ ) and other pollutants. As a result, the lakes system is characterized by high turbidity (Secchi disk depth $<1 \mathrm{~m}$ in summer), high trophic level (Chl-a up to $200 \mathrm{mg} \mathrm{m}^{-3}$ ), and the coexistence of phytoplankton and macrophytes, comprising emergent, submerged, floating-leaved and free-floating species (Pinardi et al., 2011; Bresciani et al., 2013; Bolpagni et al., 2014; Villa et al., 2015).

The sacred lotus (Nelumbo nucifera Gaertn. Nelumbonaceae), an allochthonous species originating from Southeast Asia, colonizes Superior Lake, forming two large macrophyte islands. The plant is rooted in the sediment and can grow in waters up to $3 \mathrm{~m}$ deep. The large, shield-shaped leaves ascend from the rhizomes on waxy, prickly stems and can rise 1-2 $\mathrm{m}$ above the water level. Various parts of the plant can be used for different purposes, including food, silk production, and medicine, as well as for esthetical reasons, mainly due to its large, beautiful flowers. Nelumbo was originally introduced to the Mantua lakes system in the 1920s, with its rhizomes proposed as an alternative food source. In the subsequent decades, it has been mainly been used for floral collection, and has spread throughout the lakes over the past five decades.

The water primrose [Ludwigia hexapetala (Hook. and Arn.) Zardini, H. Y. Gu and P. H. Raven Onagraceae], native to South America, is the other allochthonous species that has spread in the lakes over the past decade, first colonizing calm water bays in the Middle Lake and more recently the riparian zones of Superior and Inferior lakes. In its native range, Ludwigia can be found in wet grasslands and wetlands, whereas in areas where it has been introduced it is able to invade lakes, slow fluvial plumes, and wetlands, and is one of the most invasive plant genera in Europe 


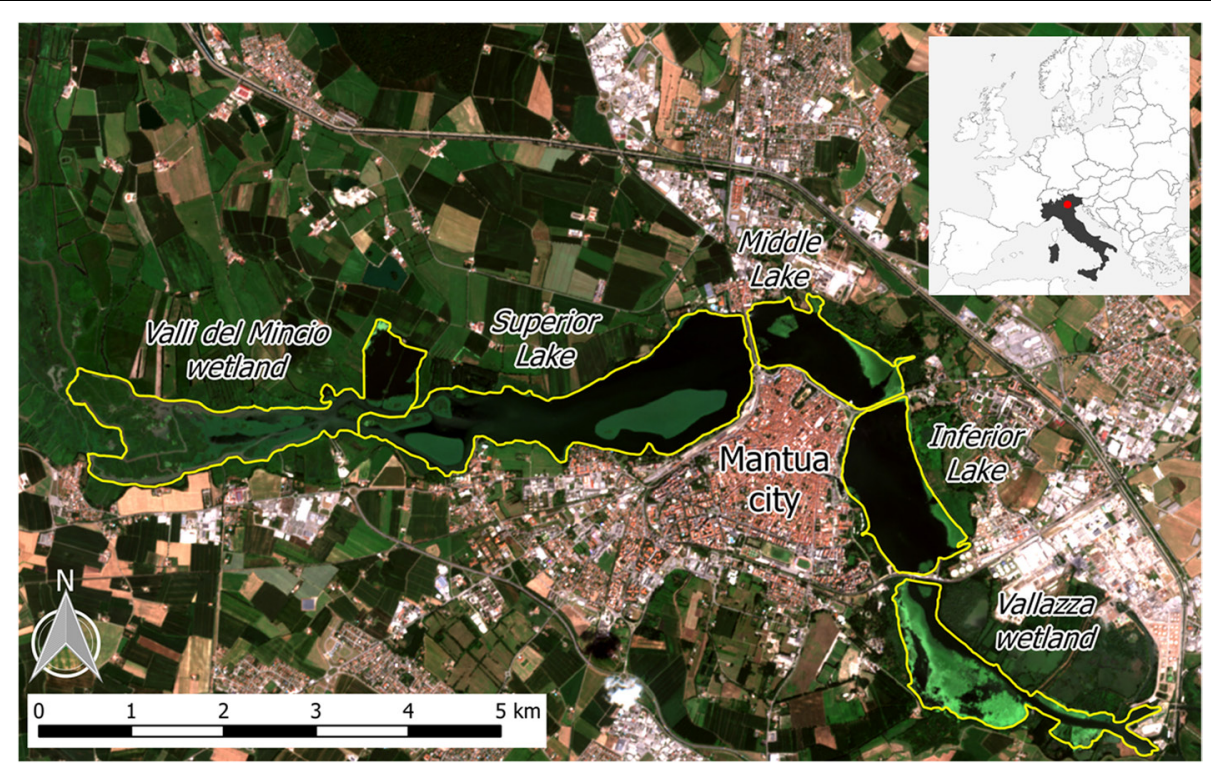

FIGURE 1 | The Mantua lakes system, with the location of the study area in Italy (upper right box), and the different subsystems (lakes and wetlands) indicated. Background image is a Sentinel-2A satellite-acquired true color composite from 28 July 2016.

(EPPO, 2004a,b). Ludwigia has large $(2-5 \mathrm{~cm})$, yellow flowers, and 8-10 cm long, spear-shaped, pilose leaves. The stem of the plant grows from 2 to 3 meter-deep water to the water surface, and can emerge above the water level.

Water chestnut (Trapa natans L. Trapanaceae) is the most widespread native species, present in all three lakes and dominant in Middle and Inferior lakes. Nymphaeids, mainly Nuphar lutea (L.) Sm Nymphaea alba L., are present in the upstream portion of Superior Lake, as well as in small patches in Middle and Inferior lakes. Submersed species (e.g., Ceratophyllum demersum L., Vallisneria spiralis L., and Najas major All.), predominantly C. demersum, are especially present in Superior Lake.

The lakes system is part of the protected Mincio Regional Park, which manages water and macrophytes. The system is characterized by high nutrient and organic matter loads and low water flow rates, resulting in its tendency toward infilling and heightened risk of hypoxia (Pinardi et al., 2011; Bolpagni et al., 2014). For this reason, since 2004, N. nucifera and T. natans macrophyte stands are controlled by cutting and occasionally harvesting (Pinardi et al., 2011; Villa et al., 2017).

We gathered limnological seasonal data (6 dates per year, ranging from February to November) and meteorological daily data (air temperature, solar radiation, precipitation, and wind velocity), collected in Mantua lakes system by the Environmental Protection Agency of Lombardy region (ARPA Lombardia) during 2016 and 2017. No significant differences in limnological parameters $\left(\mathrm{pH}\right.$, water temperature, dissolved $\mathrm{O}_{2}$, total $\mathrm{N}$, and total P) across the three lakes were observed for the two seasons (data not shown).

\section{Photophysiological Measurements}

Chlorophyll fluorescence parameters were measured using a chlorophyll fluorometer (PAM-2500, Heinz Walz GmbH,
Germany) between 9 and 15 h. Light response curves, i.e., the electron transport rate (ETR) of the photosystem II (PSII), as a function of photosynthetically active radiation (PAR) were measured from mature, healthy-looking leaves after a dark-adapting period of $20 \mathrm{~min}$. After dark adaptation, emitted initial fluorescence yield $\left(\mathrm{F}_{\mathrm{o}}\right)$ and maximal fluorescence yield $\left(\mathrm{F}_{\mathrm{m}}\right)$ resulting from a pulse of a saturated light $\left(630 \mathrm{~nm}\right.$, intensity $\left.3000 \mu \mathrm{mol} \mathrm{m} \mathrm{m}^{-2} \mathrm{~s}^{-1}\right)$ were determined. From these, the photochemical PSII efficiency $\left(\mathrm{F}_{\mathrm{v}} / \mathrm{F}_{\mathrm{m}}\right)$, coefficient of photochemical quenching $(\mathrm{qP})$, and coefficient of non-photochemical quenching ( $\mathrm{qN}$ ) were calculated. The measured leaves were exposed to 11 actinic lights $(630 \mathrm{~nm})$ for a duration of $15 \mathrm{~s}$, with an intensities between 5 and $787 \mu \mathrm{mol} \mathrm{m} \mathrm{m}^{-2} \mathrm{~s}^{-1}$, and the ETR values were measured after each illumination step with a new pulse of saturated $\left(3000 \mu \mathrm{mol} \mathrm{m} \mathrm{m}^{-2} \mathrm{~s}^{-1}\right)$ light. Exponentially saturating curves (Eilers and Peeters, 1988) were fit to the light response data, and the maximum ETR $\left(\mathrm{ETR}_{\max }\right)$, theoretical saturation light intensity $\left(\mathrm{I}_{\mathrm{k}}\right)$, and maximum quantum yield for whole chain electron transport $(\alpha)$ were retrieved (Genty et al., 1989).

\section{Pigment Analysis}

Leaf discs of $0.6 \mathrm{~cm}$ in diameter were collected from intact leaves close to where chlorophyll fluorescence was measured, and stored in aluminum foil in sub 0 temperature until their transfer to a $-20^{\circ} \mathrm{C}$ freezer. Frozen leaf discs samples were homogenized in liquid $\mathrm{N}_{2}$, then extracted in $80 \%$ acetone. The extracts were centrifuged and the supernatant collected and stored at $-20^{\circ} \mathrm{C}$ until analyses. The absorbance spectra (400-750 nm) of extracts were measured using a spectrophotometer (Shimadzu UV-2401PC, dual-beam), and 
pigment concentrations, i.e., chlorophyll-a (Chl-a), chlorophyllb (Chl-b), and total carotenoids (Car) were calculated using empirical formulae (Wellburn, 1994) and reported as fresh weight concentrations $\left(\mu \mathrm{g} \mathrm{g}_{\mathrm{fw}}{ }^{-1}\right)$.

\section{Spectroradiometric Measurements}

Leaf reflectance of the same leaves sampled for photophysiological measurements was measured over the visible to shortwave infrared spectral range $(350-2500 \mathrm{~nm})$ using a portable SR-3500 Full Range spectroradiometer (Spectral Evolution, Lawrence, United States). Following a 20-min dark adaptation period, leaf-reflected radiance under near-steady state conditions (60 s after leaf de-shadowing) was measured using a Reflectance Contact Probe (Spectral Evolution, Lawrence, United States). The probe was equipped with a light source (5-watt tungsten halogen bulb) and spectra were calibrated to leaf reflectance using measurements of a 99\% Spectralon panel (Labsphere, North Sutton, United States). During measurements, macrophyte leaves were placed over a flat neoprene plate (absorbance $>95 \%$ ) in order to minimize background reflection of light transmitted through the leaves. This approach was chosen because it is easier and faster under challenging field conditions (e.g., boat-based surveys) compared with using an integrating sphere to fully determine reflectance and transmittance, and only introduces minimal distortion in leaf reflectance measurements (Sims and Gamon, 2002; Potúčková et al., 2016).

Leaf reflectance spectra were used to calculate a set of spectral indices (SIs), belonging to three different groups: (1) SIs sensitive to photosynthetic pigments (Gitelson et al., 2001, 2003; Sims and Gamon, 2002); (2) SIs connected to radiation use efficiency (RUE) and the state of the xanthophyll cycle pigments (Gamon et al., 1992; Wu et al., 2010; Garrity et al., 2011; Hernández-Clemente et al., 2011); and (3) SIs correlated to macrophyte, Phragmites australis (common reed), physiological parameters (Stratoulias et al., 2015). The SIs tested in this study, with their formulas and relevant references are provided in Supplementary Table S1.

In order to focus on the most relevant leaf spectral features, the collinearity of all SIs tested was assessed by computing the correlation coefficient (Pearson's $r$ ) of each SI pair (Supplementary Figure S1). Only the SIs carrying the most information were retained for further analysis and discussion, by excluding the ones with $r>0.9$.

\section{Summary of in situ Measurements}

Leaf samples were measured in the Mantua lakes system in late July, 2016 - photophysiological $(n=51)$ and spectroradiometric measurements $(n=45)$ - late May, 2017 - photophysiological $(n=67)$, pigments $(n=45)$ and spectroradiometric measurements $(n=42)$ - and late July, 2017 - photophysiological $(n=71)$, pigment $(n=71)$ and spectroradiometric measurements $(n=68)$ - covering different years and growing stages. For each period, slightly different sets of sampling sites were visited, due to logistic and technical constraints. A summary of sampled sites and number of samples collected is provided in Supplementary Table S2. Leaves were collected from plants located within 2-3 $\mathrm{m}$ of the water edge of homogenous, dense, intact macrophyte stands. For in situ measurements, from each plant the youngest, mature, intact leaf was chosen. At each sampling site, 3 to 12 plants per species were selected (Supplementary Table S2). Following dark adaptation, whole leaves (for Ludwigia and Trapa) or leaf parts (for Nelumbo, Nuphar, and Nymphaea) were removed from the plants and subjected to measurements. Chlorophyll fluorescence measurements were performed on the dark-adapted part of the leaves, with leaf spectroradiometric reflectance recorded in its close vicinity. In order to avoid possible bias due to light environment differences, only leaves exposed directly to sunlight were measured.

\section{Seasonal Dynamics}

Additional information highlighting key macrophyte phenological characteristics were extracted from macrophyte leaf area index (LAI) seasonal dynamics maps. Time series of LAI for floating and emergent macrophytes in the Mantua lakes system were derived from medium resolution satellite data (Landsat 8, SPOT5, and Sentinel-2) for the 2015 growing season (Villa et al., 2018). From these time series, seasonal dynamics metrics were computed, namely: the day of the start of season (SoS), the day of the peak of season (PoS), the day of the end of season (EoS), the duration of the growing season (Length), the maximum LAI value $\left(\mathrm{LAI}_{\max }\right)$, the rate of increase of LAI during the early growth (Growth rate), and the rate of decrease of LAI during the senescence (Senescence rate).

We calculated the mean and standard deviation scores of these seasonality metrics of all pixels dominated by each macrophyte species considered in this work, as well as the area covered by each species and the corresponding percentage of total macrophyte cover. Nymphaea pixels are grouped together with Nuphar pixels, because they only cover a very small area ( $<1 \mathrm{ha})$.

\section{Statistical Analyses}

Graphing, curve fitting, and statistics were performed in Past (Hammer et al., 2001) and various packages in R v.3.4.4, i.e., stats 3.5.2, ggplot2 3.1.0, psych 1.8.12 (R Development Core Team, 2012). Due to non-normality of sample distributions, differences among species in terms of investigated parameters were tested using Kruskal-Wallis One Way Analysis of Variance on Ranks, followed by pairwise multiple comparison procedures (Dunn's Method). For each species, Mann-Whitney $U$ test was used for testing the differences of investigated parameters between July 2016 and July 2017, as well as between May 2017 and July 2017 conditions. Only relevant information, i.e., rejecting the hypothesis of equal distribution among compared samples at confidence level higher than 5\% $(P<0.05)$, is reported in the following section, describing the main results.

\section{RESULTS}

\section{Photophysiological Measurements}

Clear differences in the photophysiological properties of the studied plants and in the photosynthetic activity of Ludwigia were observed (Supplementary Figure S2; Figures 2B,C). Not only did the extent of $\mathrm{ETR}_{\max }$ and $\mathrm{I}_{\mathrm{k}}$ differ significantly for 

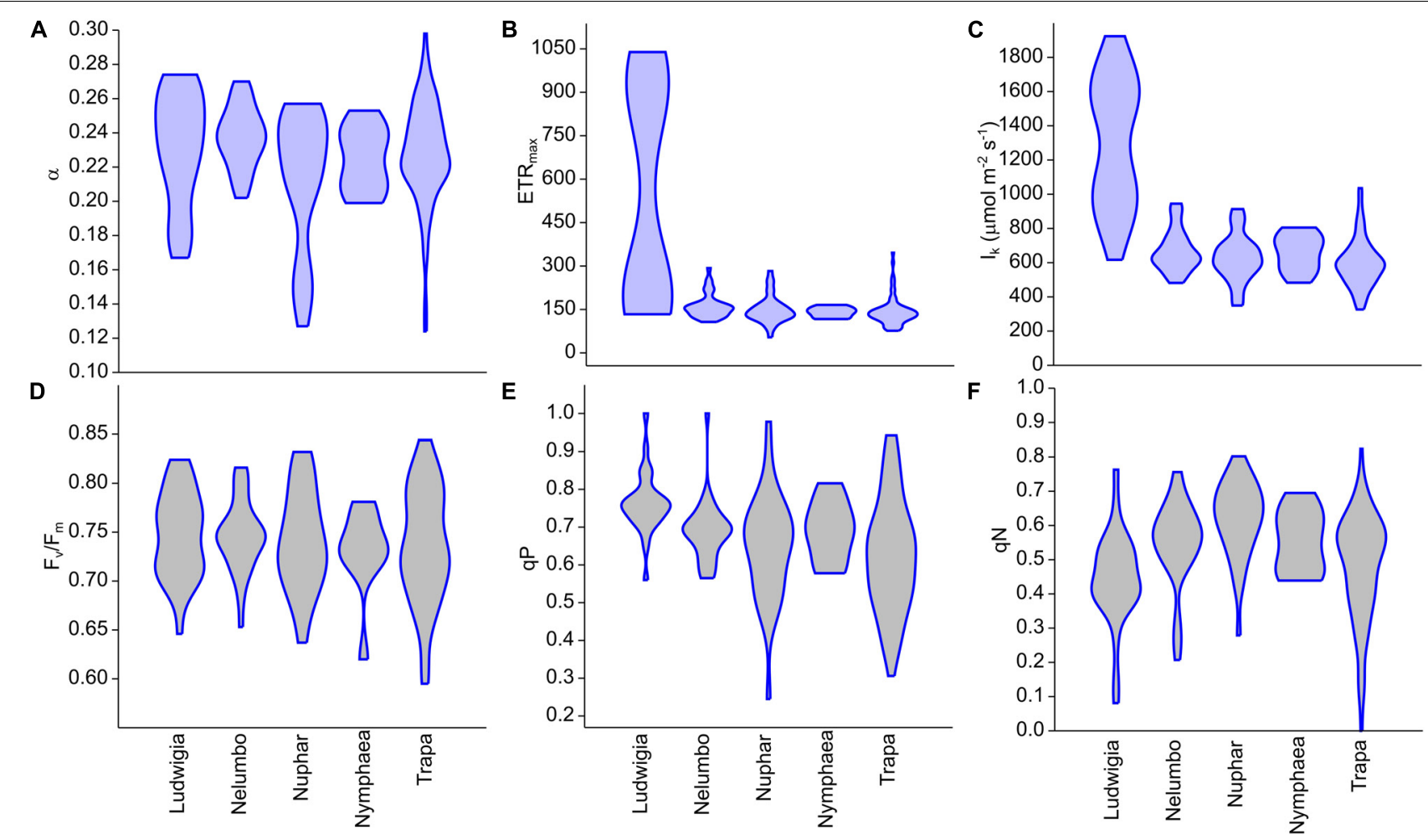

FIGURE 2 | Chlorophyll fluorescence parameters measured from Mantua lakes system macrophytes. (A) maximum quantum yield for whole chain electron transport $(\alpha)$, (B) maximal electron transport rate $\left(E T R_{\max }\right)$, (C) theoretical saturation light intensity $\left(\mathrm{l}_{\mathrm{K}}\right)$, (D) PSIl photochemical efficiency $\left(\mathrm{F}_{\mathrm{v}} / \mathrm{F}_{\mathrm{m}}\right)$, (E) coefficient of photochemical quenching (qP), and (F) coefficient of non-photochemical quenching (qN).

Ludwigia with respect to the rest of the species (Kruskal-Wallis One Way Analysis of Variance on Ranks; $H=57.2 ; P<0.001$; $n=182$ ), but their distributions were bimodal, suggesting the presence of two subgroups (Figure 2). These separate Ludwigia subgroups can partially be explained by the marked differences between 2016 and 2017 samples: ETR $\max$ scores for Ludwigia are in fact significantly lower in July 2016 than in July 2017, $162.2 \pm 15.9$ and $743.4 \pm 290.2 \mu \mathrm{mol} \mathrm{m} \mathrm{m}^{-2} \mathrm{~s}^{-1}$ respectively (Mann-Whitney $U$ test; $U=0 ; P<0.001 ; n_{1}=n_{2}=9$ ). Due to this difference in $\mathrm{ETR}_{\max }$ and in $\mathrm{I}_{\mathrm{k}}$, the position of Ludwigia in the photophysiological PCA was well defined (Figure 3).

The photophysiological properties of Nelumbo did not differ from those of the local macrophytes, therefore Nelumbo aligned with the rest of the species present within the PCA. Further analysis of the photophysiological parameters of the studied macrophytes demonstrated the higher plasticity of Ludwigia, Trapa, and Nuphar compared with Nymphaea and Nelumbo (Table 1).

\section{Pigment Analysis}

Chl-a, Chl-b, and Car content of Nelumbo and Ludwigia on weight basis were significantly higher than those of other species (Figures 4A-C; Kruskal-Wallis One Way Analysis of Variance on Ranks; $P<0.001)$. Ludwigia Chl-a content was higher in May than in July, $2001 \pm 258$ compared with $1591 \pm 313 \mu \mathrm{g}$ $\mathrm{g}_{\mathrm{fw}}{ }^{-1}$ (Mann-Whitney $U$ test; $U=11 ; P=0.01 ; n_{1}=n_{2}=9$ ).
Nevertheless, despite the higher pigment content - Ludwigia and Nelumbo had, on average, 2.8, 2.7, and 2.4 times higher Chl-a, Chl-b, and Car content than Nymphaea, Nuphar, and Trapa, respectively, the Chl-a/ Chl-b ratio (a/b) of Ludwigia alone differed significantly $(P<0.05)$ from that of Nelumbo, Nuphar, and Nymphaea, and was similar to that of Trapa (Figure 4D). The total chlorophyll (Chl-a + Chl-b) to Car ratio (chl/car) of Nymphaea was significantly lower $(2.18 \pm 0.05)$ than the rest of the species $(3.56 \pm 0.05)$. Due to the significant difference of Ludwigia and Nelumbo from native species in leaf pigments content, their discrimination was clearly defined through PCA (Figure 5). Further analysis of pigment content results showed high phenotypic plasticity of Chl-a, Chl-b, and Car content for both Ludwigia and Nelumbo, although pigment stoichiometry was also variable for Nuphar and Trapa (Table 1).

\section{Spectroradiometric Measurements}

After assessing the cross-correlation of tested SIs for the sampled species (Supplementary Figure S1), some indices were excluded from further analyses. The list of SIs tested, with their full names and relevant references are included in Supplementary Table S1. Revised Photochemical Reflectance Index $2\left(\mathrm{PRI}_{\mathrm{r} 2}\right)$ and Photochemical Reflectance Index combination with Chlorophyll Index $\left(\mathrm{PRI}^{*} \mathrm{CI}\right)$ were excluded because of their high correlation with Photochemical Reflectance Index (PRI; $r=0.94$ and $r=0.95$, respectively, Figures 6, 7). Normalized Difference 


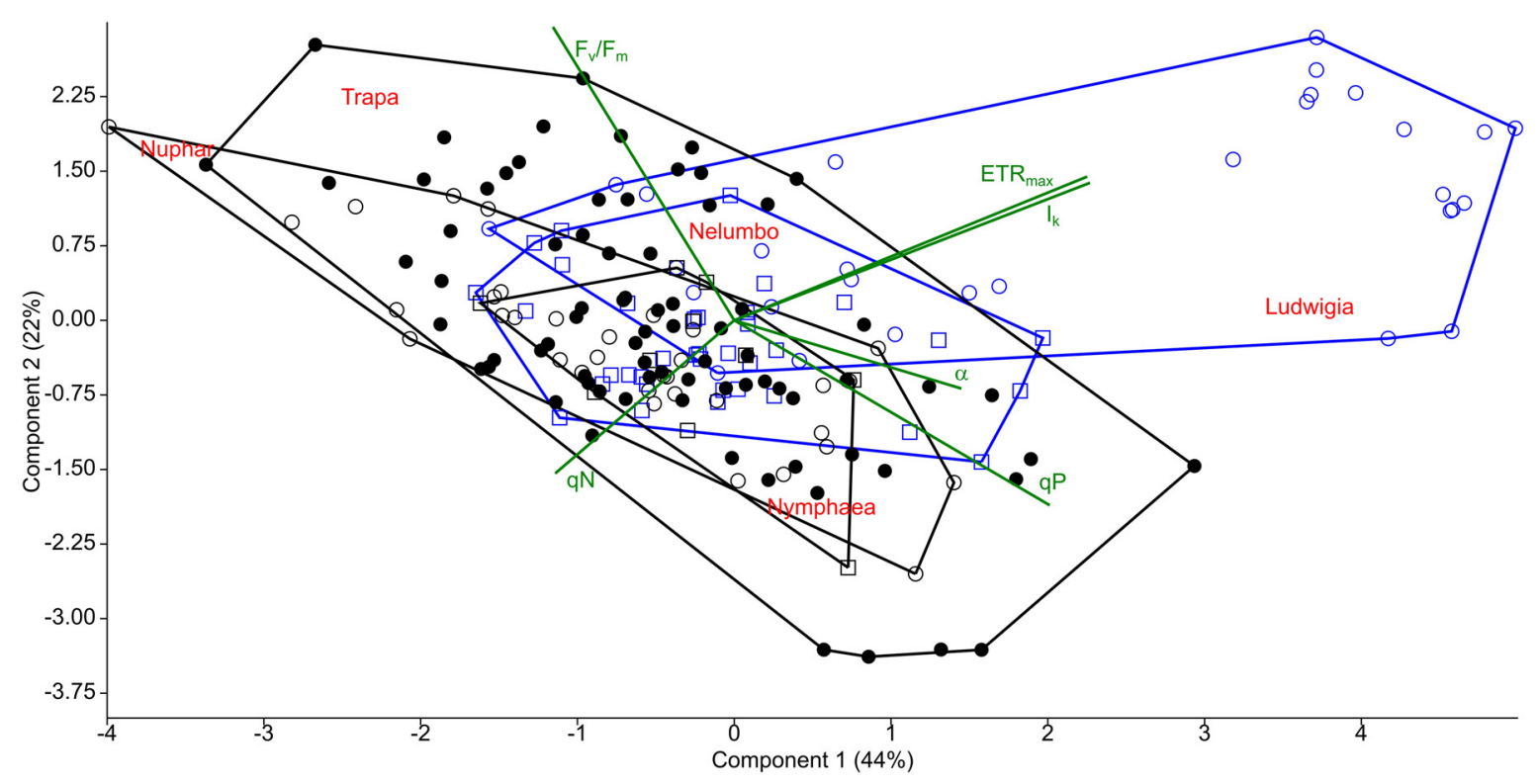

FIGURE 3 | Principal component analysis (PCA) of photophysiological parameters measured from macrophytes of the Mantua lakes system. $\alpha$, maximum quantum yield for whole chain electron transport; ETRmax, maximal electron transport rate; $l_{k}$, theoretical saturation light intensity; $F_{v} / F_{m}$, PSII photochemical efficiency; qP, coefficient of photochemical quenching; and qN, coefficient of non-photochemical quenching.

TABLE 1 | Coefficient of variation of the standardized pigment and photophysiological data of Mantua lakes system macrophytes.

\begin{tabular}{|c|c|c|c|c|c|c|c|c|c|c|c|}
\hline Species & chl-a & chl-b & car & $a / b$ & chl/car & $\alpha$ & ETR $_{\max }$ & $I_{k}$ & $\mathbf{F}_{\mathrm{v}} / \mathrm{F}_{\mathrm{m}}$ & $\mathrm{qN}$ & qP \\
\hline Ludwigia & 0.26 & 0.46 & 0.18 & 0.84 & 0.35 & 1.14 & 3.11 & 1.41 & 0.75 & 0.83 & 0.36 \\
\hline Nelumbo & 0.41 & 0.40 & 0.33 & 0.31 & 0.24 & 0.34 & 0.04 & 0.15 & 0.53 & 0.70 & 0.35 \\
\hline Nuphar & 0.05 & 0.09 & 0.08 & 1.08 & 0.22 & 1.66 & 0.05 & 0.20 & 1.03 & 0.57 & 1.10 \\
\hline Nymphaea & 0.02 & 0.03 & 0.05 & 0.41 & 0.08 & 0.38 & 0.01 & 0.12 & 0.78 & 0.40 & 0.37 \\
\hline Trapa & 0.04 & 0.07 & 0.04 & 0.75 & 0.56 & 0.93 & 0.05 & 0.21 & 1.35 & 1.11 & 1.28 \\
\hline
\end{tabular}

chl-a, chlorophyll a content; chl-b, chlorophyll b content; car, total carotenoids content; a/b, chlorophyll a to chlorophyll b ratio; chl/car, chlorophylls to carotenoids ratio;

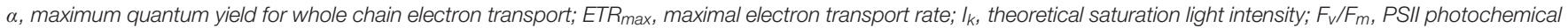
efficiency; qN, coefficient of non-photochemical quenching; and qP, coefficient of photochemical quenching.

Spectral Index 539,560 (ND 539,560$)$ was also not considered further due to its high correlation with PRI $(r=0.92)$. Within the macrophyte eco-physiology sensitive SIs, Normalized Difference Spectral Index 659,687 $\left(\mathrm{ND}_{659,687}\right)$ and Normalized Difference Spectral Index 621,692 ( $\left.\mathrm{ND}_{621,692}\right)$ were found to be highly correlated $(r=0.91)$, so we therefore only retained the latter for further analysis. Finally, we excluded Normalized Difference $750 / 705\left(\mathrm{ND}_{705}\right)$ due to its high correlation with modified Normalized Difference $750 / 705\left(\mathrm{mND}_{705} ; r=0.84\right)$, and Chlorophyll Index (CI) due to its lower sensitivity to leaf chlorophyll content compared to $\mathrm{mND}_{705}(r=0.41-0.42$ and $r=0.77-0.78$ respectively).

Within our dataset, there is a significant difference in PRI between the species (Kruskal-Wallis One Way Analysis of Variance on Ranks; $H=45.8 ; P<0.001 ; n=152)$. PRI of Nelumbo samples was higher (Dunn's Multiple Comparison test, $P<0.05$ ) than that of Trapa, Nuphar, and Nymphaea, while Ludwigia was not found to be significantly different, although on average PRI was lower. Photochemical Reflectance Index $515\left(\mathrm{PRI}_{515}\right)$ differs from PRI especially for the allochthonous species, and in particular for Nelumbo, which shows significantly lower $\mathrm{PRI}_{515}$ scores compared to the autochthonous species (Dunn's Multiple Comparison test, $P<0.05$ ).

Nelumbo is statistically different from all the other species (Dunn's Multiple Comparison test; $P<0.05)$ in terms of Normalized Difference Spectral Index 546,551 (ND 546,551 ), and is different from the autochthonous species (Dunn's Multiple Comparison test; $P<0.05$ ) in terms of $\mathrm{ND}_{621,692}$. Even though not statistically significant, $\mathrm{ND}_{621,692}$ scores for Ludwigia are also slightly lower than those of the autochthonous species $(0.055 \pm 0.021$ and $0.076 \pm 0.034$, respectively, in July 2017).

Anthocyanin reflectance index $2\left(\mathrm{ARI}_{2}\right)$, which is related to secondary pigment contents, showed no difference between the species (Kruskal-Wallis One Way Analysis of Variance on Ranks; $H=6.748 ; P=0.150 ; n=152$ ). Rather, significant differences between the species are observed for $\mathrm{mND}_{705}$, related to total chlorophyll content (Kruskal-Wallis One Way Analysis of Variance on Ranks; $H=31.5 ; P<0.001 ; n=152$ ), with Nelumbo showing higher values compared to any other species (Dunn's Multiple Comparison test, $P<0.05$ ). 


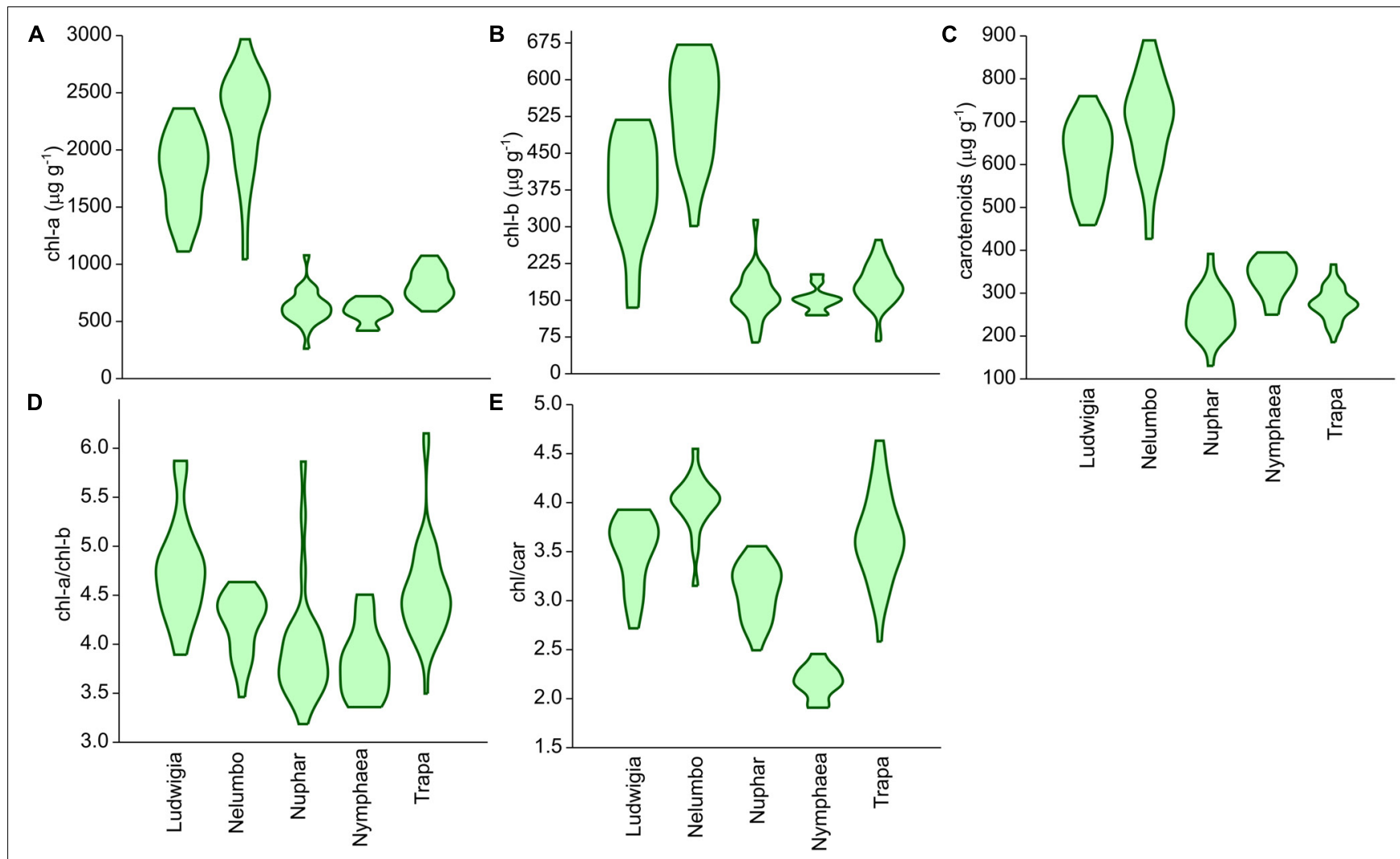

FIGURE 4 | Leaf pigment contents of macrophytes of the Mantua lakes system, reported as a function of fresh weight. (A) chlorophyll a content (chl-a; $\mu \mathrm{g} \mathrm{g}_{\mathrm{fw}}{ }^{-1}$ ), (B) chlorophyll b content (chl-b; $\mu \mathrm{g} \mathrm{g}_{\mathrm{fw}}{ }^{-1}$ ), (C) total carotenoids content (carotenoids; $\mu \mathrm{g} \mathrm{g}_{\mathrm{fw}}{ }^{-1}$ ), (D) chlorophyll a to chlorophyll b ratio (chl-a/chl-b), (E) chlorophylls to carotenoids ratio (chl/car).

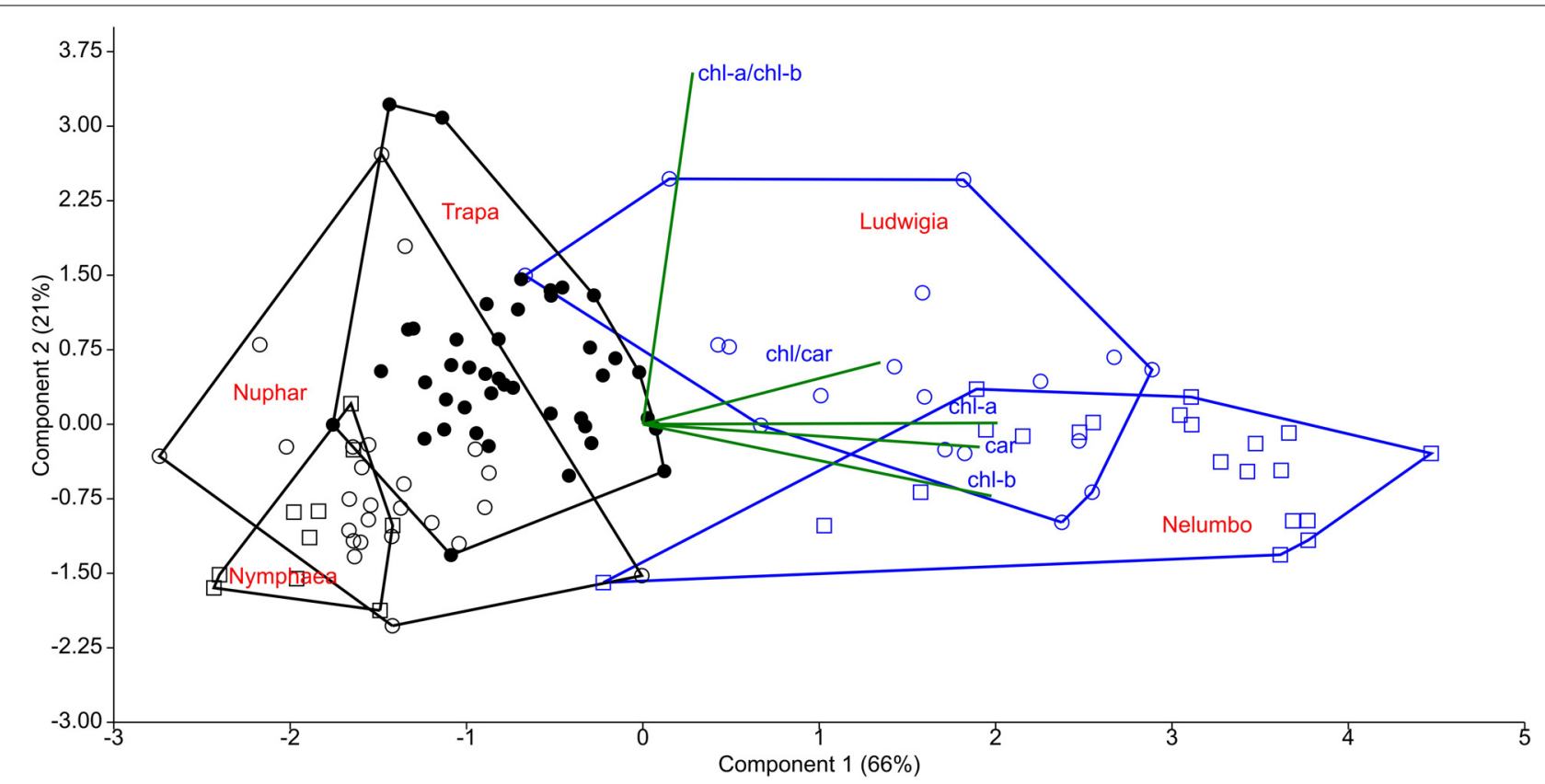

FIGURE 5 | Principal component analysis (PCA) of leaf pigment content of macrophytes of the Mantua lakes system. chl-a, chlorophyll a content; chl-b, chlorophyll b content; car, total carotenoids content; chl-a/chl-b, chlorophyll a to chlorophyll b ratio; and chl/car, chlorophylls to carotenoids ratio. 

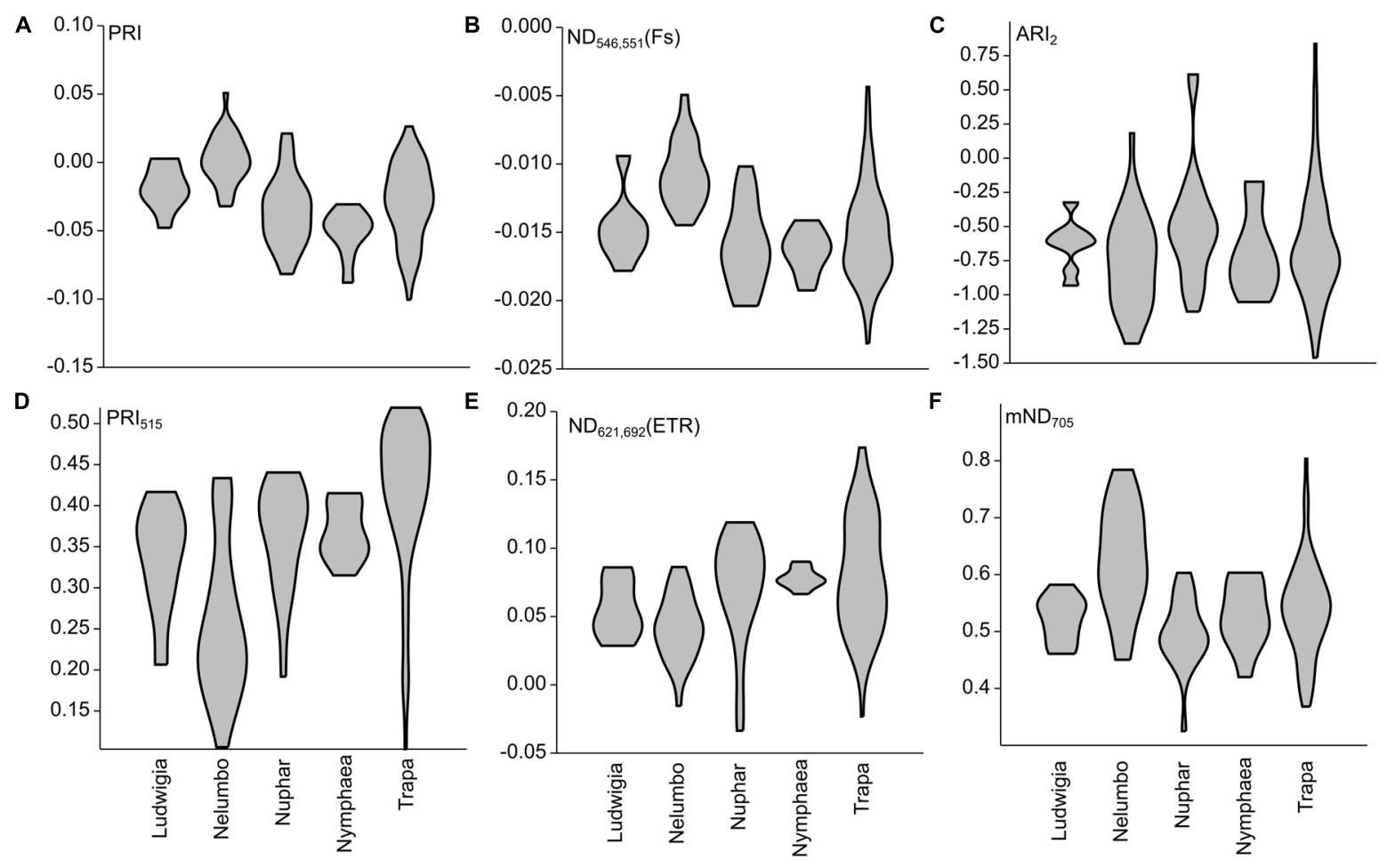

FIGURE 6 | Selected Sls calculated from Mantua lakes system macrophyte leaf reflectance data of. (A) Photochemical reflectance index (PRI); (B) Normalized difference spectral index 546,551 (ND546,551); (C) Anthocyanin reflectance index 2 (ARI 2$)$; (D) Photochemical reflectance index 515 (PRl 515$)$; (E) Normalized difference spectral index 621,692 ( $\left(\mathrm{ND}_{621,692}\right)$; and (F) modified normalized difference 750/705 ( $\left.\mathrm{mND}_{705}\right)$.

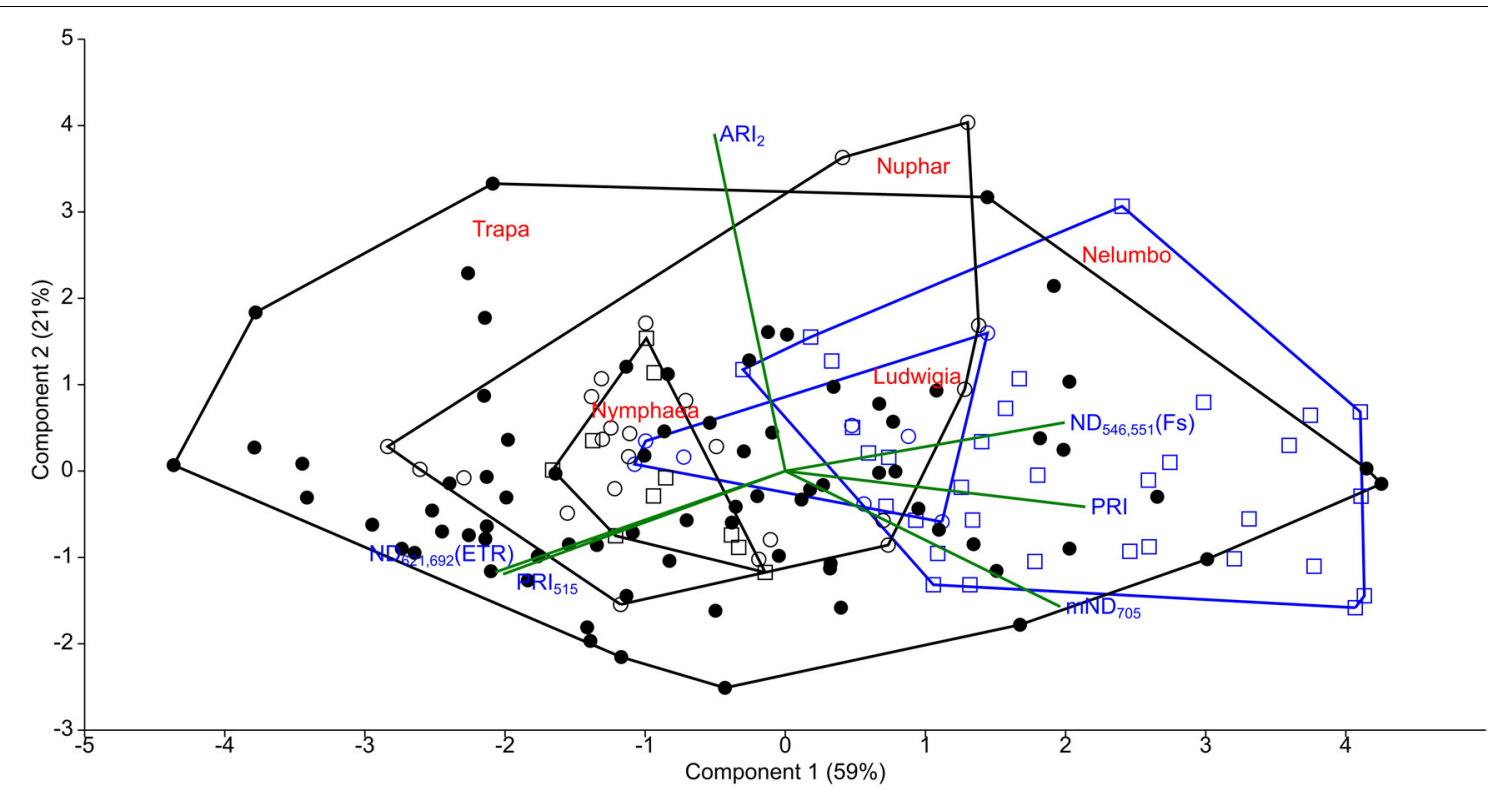

FIGURE 7 | Principal component analysis (PCA) of selected Sls calculated from Mantua lakes system macrophyte leaf reflectance data. PRI, photochemical reflectance index; $\mathrm{ND}_{546,551}$, normalized difference spectral index 546,551; $\mathrm{ARI}_{2}$, anthocyanin reflectance index 2; $\mathrm{PR} \mathrm{I}_{515}$, photochemical reflectance index 515 ; Normalized $\mathrm{ND}_{621,692}$, difference spectral index 621,692; and mND 705 , modified normalized difference 750/705. 


\section{Seasonal Dynamics Features}

Differences between allochthonous and autochthonous species, in terms of their seasonal dynamics, or phenology metrics - i.e., day of the start (SoS), peak (PoS), and end of season (EoS), as well as the length of growing season - are highlighted in Table 2, referring to 2015 growing season. Peak LAI values $\left(\mathrm{LAI}_{\max }\right)$ and LAI growth and senescence rates ( $\left.\mathrm{LAI}_{\text {growth }}, \mathrm{LAI}_{\text {senescence }}\right)$ were also calculated.

The growing season of allochthonous species was found to be significantly longer than that of native species: $192 \pm 15$ days for Ludwigia (Mann-Whitney $U$ test; $U=12853 ; P<0.001 ; n_{1}=58$, $n_{2}=2249$ ), and $172 \pm 5$ days for Nelumbo (Mann-Whitney $U$ test; $\left.U=128812 ; P<0.001 ; n_{1}=2024, n_{2}=2249\right)$. Such differences in season length is mainly driven by prolonged viability of allochthonous macrophytes during autumn months, lasting over water until late October to mid-November. Nelumbo also shows morphological advantages, with maximal leaf area index $\left(\mathrm{LAI}_{\max }\right.$ ) reaching $1.7 \mathrm{~m}^{2} \mathrm{~m}^{-2}$ at $\mathrm{PoS}$, significantly higher that of all the other species, reaching $1.0-1.2 \mathrm{~m}^{2} \mathrm{~m}^{-2}$ (Mann-Whitney $U$ test; $U=280047 ; P<0.001 ; n_{1}=2024$, $n_{2}=2307$ ), as well as fast early season growth, with $\mathrm{LAI}_{\text {growth }}-$ i.e., the rate of LAI growth from SoS to PoS - higher by 2-3 times compare to that of the other species (Mann-Whitney $U$ test; $\left.U=438004 ; P<0.001 ; n_{1}=2024, n_{2}=2307\right)$.

\section{DISCUSSION}

The background and dynamics of invasion processes are still a matter of debate. Nevertheless, studies focusing on morphological and physiological characteristics of native and invasive plants can elucidate the success of the latter (Baruch and Goldstein, 1999; Hufbauer and Torchin, 2008; Van Kleunen et al., 2010). While a given explanation of how morphological and physiological parameters can promote the spread of non-native species might only be applicable to the ecosystem in question, some of the observations could be considered to be more generally valid. For example, higher photosynthetic rates of invasive plants could result in higher biomass accumulation, consequently exhausting resources available for native species and/or shading out native competitors
(Baruch and Goldstein, 1999; Hufbauer and Torchin, 2008). To our first hypothesis, we have a partial answer: of all the species investigated, Ludwigia had the highest photosynthetic parameters $\left(\mathrm{ETR}_{\max }, \mathrm{I}_{\mathrm{k}}\right)$, which is in line with its $\mathrm{C}_{4}$ nature and high photosynthesis rates (Dandelot et al., 2005; Hussner, 2009), although this does not always translate into higher biomass (Hussner, 2009). It is worth noting that in the Mantua lakes system, Ludwigia samples showed a strong response to environmental changes. One of the explanations of the outstanding bimodality of $\mathrm{ETR}_{\max }$ and $\mathrm{I}_{\mathrm{k}}$ for this species could be the inter-seasonal differences between 2016 and 2017, linked to differences in meteorological conditions accumulated up to late July for the 2 years. When compared to 2016, 2017 was much drier (total precipitation 52\% lower), hotter (average max temperature higher by $0.9^{\circ} \mathrm{C}$, or $4.6 \%$ ), and with higher incoming radiation (by 5.9\%), as shown in Supplementary Figure S3. Nevertheless, intra-seasonal differences also reveal that other factors (e.g., water and sediment conditions, prevalence of growth form) should be taken into account to explain Ludwigia ecotype specialization (Thouvenot et al., 2013; Gérard et al., 2014). Interestingly, other Ludwigia photophysiological parameters $(\alpha$, $\mathrm{F}_{\mathrm{v}} / \mathrm{F}_{\mathrm{m}}$, and $\mathrm{qP}$ ) did not differ significantly from those of other species; only its $\mathrm{qN}$ was slightly lower than the other macrophytes, highlighting the higher efficiency of Ludwigia in dissipating excitation energy through photosynthesis.

The photophysiological response of Ludwigia to the anomalous meteorological conditions of 2017 can be compared to those of the most-abundant native species in Mantua lakes system: Trapa. Both species showed consistent responses to such environmental conditions, in terms of $\mathrm{F}_{\mathrm{v}} / \mathrm{F}_{\mathrm{m}}$ and $\mathrm{qP}$, with a tendency toward slightly lower scores in 2017 than in 2016. Inversely, the two species reacted differently to the dry and hot weather of 2017, in terms of non-photochemical quenching (qN). Compared to July 2016, Trapa samples measured in July 2017 tend to have higher $\mathrm{qN}$, while Ludwigia had lower levels of non-photochemical quenching in 2017 than in 2016. The reaction of Ludwigia to anomalously dry and hot conditions could in part explain the competitive success and invasiveness of water primrose in temperate areas of Europe.

On the other hand, absolute photosynthesis and biomass accumulation values are not the only features underlying the

TABLE 2 | Synoptic metrics of seasonal dynamics (phenology and LAl growth) for Mantua lakes system macrophytes for 2015, derived from Villa et al. (2018).

\begin{tabular}{|c|c|c|c|c|}
\hline & Ludwigia & Nelumbo & Nuphar-Nymphaea & Trapa \\
\hline SoS (DOY - Julian day) & $122.5 \pm 6.4$ & $132.4 \pm 3.9$ & $115.1 \pm 8.0$ & $155.2 \pm 16.6$ \\
\hline PoS (DOY - Julian day) & $222.3 \pm 6.9$ & $218.6 \pm 4.0$ & $200.6 \pm 13.3$ & $215.8 \pm 13.0$ \\
\hline EoS (DOY - Julian day) & $314.8 \pm 13.2$ & $304.4 \pm 3.9$ & $263.1 \pm 20.4$ & $256.7 \pm 13.2$ \\
\hline Length (days) & $192.3 \pm 14.8$ & $172.0 \pm 5.2$ & $147.9 \pm 28.1$ & $101.5 \pm 9.7$ \\
\hline$L A I_{\max }\left(m^{2} m^{-2}\right)$ & $1.15 \pm 0.28$ & $1.69 \pm 0.05$ & $1.06 \pm 0.18$ & $1.28 \pm 0.13$ \\
\hline Growth rate $\left(\mathrm{m}^{2} \mathrm{~m}^{-2} \mathrm{~d}^{-1}\right)$ & $0.018 \pm 0.007$ & $0.047 \pm 0.008$ & $0.015 \pm 0.005$ & $0.023 \pm 0.004$ \\
\hline Senescence rate $\left(m^{2} m^{-2} d^{-1}\right)$ & $0.013 \pm 0.004$ & $0.026 \pm 0.004$ & $0.018 \pm 0.006$ & $0.045 \pm 0.018$ \\
\hline Area (ha) & 2 & 69 & 9 & 74 \\
\hline$\%$ cover of total macrophytes & 1.3 & 44.8 & 5.8 & 48.1 \\
\hline
\end{tabular}

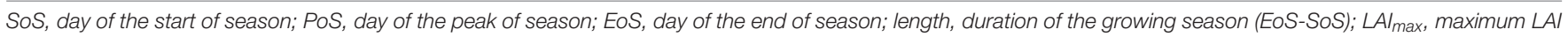
value; growth rate, rate of increase of $L A l$ during the early growth; and senescence rate, rate of decrease of $L A l$ during the senescence. 
success of invasive species. The ability to survive, and even to thrive, in very different environmental conditions could be part of invasive species' advantage, allowing their spread in areas where they have been introduced. We also hypothesized that invasive plant will have higher phenotypic plasticity. Again, when we consider the variability of Ludwigia, we found this species to be distinctive, in that its coefficients of variation for ETR $_{\max }$ and $\mathrm{I}_{\mathrm{k}}$ were at least 62 and 7 times higher than any other species, respectively (Table 1). This extreme plasticity could help Ludwigia to survive in highly variable conditions encountered in both its native range and in areas to which it is introduced. The other species showing high photophysiological variability was Trapa (in terms of $\mathrm{F}_{\mathrm{v}} / \mathrm{F}_{\mathrm{m}}, \mathrm{qP}, \mathrm{qN}$ ), showing its ecological advantage in the Mantua lakes system and explaining its spread in the study area (i.e., nearly half of the total macrophyte-covered surface). The combination of the above make it evident that, in the end, these traits of Ludwigia or Trapa would largely determine the structure and diversity of the Mantua lakes system macrophyte communities. The results also showed that higher plasticity in a community could be an important determinant of the diversity of a given species. This plasticity helps the species to overcome environmental factors that might otherwise limit its spread in the given environment (Lankau, 2011; Andersen et al., 2012). Not only does the lower mortality at population level undoubtedly result in either higher density and coverage or spatial spreading, but the high variability of functional traits is considered to be an advantage for species establishment and survival (Levine and HilleRisLambers, 2009; Lankau, 2011).

We also hypothesized that leaf pigment pools of invasive plants are different in size and composition from native ones. Another key feature facilitating invasive plants in their new environments is the lack of top-down pressure (specific herbivores), and thus the absence of structural defense biomass (Feng et al., 2009; Rout and Callaway, 2009). This results in the preferential allocation of $\mathrm{N}$ from structural biomass into leaf tissues and photosystems in invasive plants, consequently increasing the non-structural, photosynthetically active biomass. Our results support this theory, since both Ludwigia and Nelumbo had significantly higher pigment content on weight basis (by at least 2-3 times) compared to the native species. The intensification of photosynthetically active biomass helped the plants to further increase the resources available to them, and consequently to extend their presence in their new areas. Besides having the highest absolute values, Nelumbo and Ludwigia also showed the most variable pigment content, suggesting that these invasive species could adapt to very different environmental conditions. The high pigment content (especially total chlorophyll) of the leaf tissues also affected the specific reflectance of the invasive species and thus the SIs.

PRI was developed and its effectiveness as a proxy for RUE (Gamon et al., 1992; Garbulsky et al., 2011) was demonstrated. Recent works and meta-analysis have shown that PRI also correlates to the seasonal dynamics of pigments pools, and in particular to the ratio of chlorophylls to carotenoids (Filella et al., 2009; Gitelson et al., 2017), and to the daily variability of photosynthetic rates (Filella et al., 2009; Gamon et al., 2015). The PRI literature mainly focuses on terrestrial plants and crops
(Garbulsky et al., 2011), and not much is known on its ranges and sensitivity for aquatic plants. Our results suggest that, among the macrophyte species considered, the invasive Nelumbo might have a higher RUE compared to the native species considered (Figure 6A). This is possibly due to its higher $\mathrm{chl} / \mathrm{car}$ ratio (Figure 4E). PRI 515 , a modification of the original PRI concept that is inversely related to total carotenoid content in terrestrial plants (Hernández-Clemente et al., 2011), shows some notable differences from PRI for allochthonous macrophytes. Nelumbo in particular has significantly lower $\mathrm{PRI}_{515}$ scores, as well as higher pigment (chlorophylls and total carotenoids; Figures 4A-C) contents, compared to other species.

Although originally developed for common reed, SIs sensitive to physiological parameters of aquatic plants (Stratoulias et al., 2015) confirm the uniqueness of Nelumbo compared to the other species, reinforcing what was already observed for PRI. This species is statistically different from all the others in terms of $\mathrm{ND}_{546,551}$, indicating higher chlorophyll fluorescence levels in light-adapted state, and from all the native species in terms of $\mathrm{ND}_{621,692}$, which can be attributed to lower values of instantaneous ETR. Even if not statistically significant at the $95 \%$ confidence level, Ludwigia $\mathrm{ND}_{621,692}$ scores are on average slightly lower than those of native species. Additionally, Nelumbo mND ${ }_{705}$ scores, related to leaf chlorophyll content in terrestrial plants (Sims and Gamon, 2002), but not yet tested on aquatic vegetation, are significantly higher than any of the other macrophytes. This is similar to the leaf pigment measurements made on our samples (Figures 4A-C).

Our results suggest that $\mathrm{mND}_{705}$ could be effectively used as a proxy for total chlorophyll content for macrophytes $\left(R^{2}=0.59\right)$, but estimation error might vary depending on species. In fact, the relationship between $\mathrm{mND}_{705}$ and pigment contents for sampled macrophytes seems to be different for autochthonous and allochthonous species (Supplementary Figures S4, S5).

It was hypothesized that invasive macrophytes can effectively exploit temporal niches left unoccupied by the seasonal dynamics of native species. Overall, the observed photophysiological and spectral reflectance parameter features point to some notable difference in photosynthetic performance of autochthonous and allochthonous species, either in terms of adaptation to anomalous environmental conditions and maximum photosynthetic rates, in the case of Ludwigia, or pigment pool size and higher RUE for Nelumbo. In addition, seasonal dynamic features (Table 2) show that both Nelumbo and Ludwigia have marked differences in season length with respect to Trapa and Nymphaeids, with the end of season delayed by approximately 40-60 days (i.e., until November), which arguably constitutes an advantage in terms of productivity.

For Nelumbo, this might be related to peculiarities in circadian clock family genes, making it easy for this species to adapt to a wide range of climates and day length regimes, with prolonged flowering times (Ming et al., 2013). In addition, morphological and structural traits (bigger leaves, emerging above water in overlapping layers; average $\mathrm{LAI}_{\max }=1.69 \mathrm{~m}^{2} \mathrm{~m}^{-2}$ ) and fast dynamics during the early vegetative phase (May-June) - with LAI $_{\text {growth }}=0.047 \mathrm{~m}^{2} \mathrm{~m}^{-2} \mathrm{dd}^{-1}$ - provide an advantage for Nelumbo in the environmental conditions of the Mantua lakes 
system, and contribute to the success of this species, now established here for approximately a century.

The notion that invasive species tend to show higher scores of functional traits, which emerged in a recent meta-analysis (Van Kleunen et al., 2010), was generally confirmed by our results for the macrophyte species investigated, especially when dealing with traits related to physiology (e.g., leaf pigment contents, $\left.\mathrm{ETR}_{\max }, \mathrm{RUE}\right)$, size $\left(\mathrm{LAI}_{\max }\right)$, growth rate

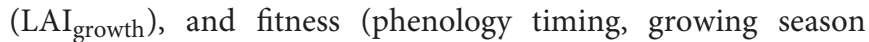
length). Ludwigia and Nelumbo, though, have been shown to outperform autochthonous plants in different group of traits, with the former having a greater advantage in terms of physiology-related traits, and the latter in terms of size and growth rate-related traits.

In summary, marked differences of Ludwigia and Nelumbo compared to native macrophytes, in terms of pigment contents (Chl-a, Chl-b, Car), growing season length, and end of season timing were observed. Parallel to this, compared to all other species, Ludwigia had the highest photophysiological parameters $\left(\mathrm{ETR}_{\max }, \mathrm{I}_{\mathrm{k}}\right)$. Differences were detected in Nelumbo compared to all other species, in terms of spectral reflectance features (i.e., PRI, $\mathrm{PRI}_{515}, \mathrm{ND}_{546,551}$, and $\mathrm{mND}_{705}$, connected to higher RUE and pigment pool size), as well as morphological and growth rate features. During the anomalously hot and dry 2017 season, invasive species were found to react differently from native species, as well as between themselves. Ludwigia performs differently in terms of $\alpha, \mathrm{qN}$, and $\mathrm{ND}_{546,551}$, linked to the variability in photosynthetic efficiency, while Nelumbo performs differently in terms of $\mathrm{PRI}_{515}$ and $\mathrm{mND}_{705}$, mainly related to pigment contents and composition. As these parameters are good indicators of enhanced productivity, such an outcome suggests that an increase in temperature, as for current climate change projections, may further favor the spread of invasive species in temperate areas.

\section{CONCLUSION}

Solar radiation is an essential resource for plants, and whichever species gain ascendancy over its competitors could be dominant. We found that the success of an invasive macrophyte, in terms of persisting and propagating in its new ecosystem, may be the result of multiple ecological strategies employed. The specificities of the new host areas (such as the lack of top-down pressure, lack of pathogens, etc.,) reduce defense costs, thus liberating resources to extend and intensify photosynthesis. This, coupled with their better ability to compete for resources and to tolerate

\section{REFERENCES}

Alahuhta, J., Kosten, S., Akasaka, M., Auderset, D., Azzella, M. M., Bolpagni, R., et al. (2017). Global variation in the beta diversity of lake macrophytes is driven by environmental heterogeneity rather than latitude. J. Biogeogr. 44, 1758-1769. Andersen, K. M., Endara, M. J., Turner, B. L., and Dalling, J. W. (2012). Trait-based community assembly of understory palms along a soil nutrient gradient in a lower montane tropical forest. Oecologia 168, 519-531. doi: 10.1007/s00442$011-2112-z$ harsh conditions, consequently improves the chances of survival of non-native species. Ludwigia hexapetala and Nelumbo nucifera have been documented to establish, spread, and alter the Mantua lakes system. Our data show that specific performance-based traits of the invasive macrophytes, photophysiological efficiency, pigment pool size and balance, and leaf spectral reflectance specifically, can describe and explain the success of these species over native ones in the same environment, in terms of both resource competitiveness and tolerance to variability in environmental conditions.

\section{AUTHOR CONTRIBUTIONS}

VT and PV designed the concept of the study, organized the databases, performed the visualization of data and statistical analysis, and wrote the first draft of the manuscript. All authors performed the measurements shown in the study, wrote parts of the manuscript, and contributed to manuscript revision, read and approved the submitted version.

\section{FUNDING}

This study was funded by grants from the Hungarian National Research, Development and Innovation Office the NKFIH K-116666 and NKFIH KH-129505, and MTA-CNR bilateral grants and agreement on scientific cooperation between the Hungarian Academy of Sciences and the Consiglio Nazionale delle Ricerche (MacroSense project). Part of the work was carried out in the context of the EU FP7 INFORM project (Grant No. 606865). Publication costs were partly covered using residual funds ("residui") from CNR project DTA.AD004.112 (Space-O).

\section{ACKNOWLEDGMENTS}

We thank the Parco del Mincio authority and voluntary ecological guards for support given during fieldwork on the Mantua lakes system. We are grateful to Stephanie C. J. Palmer for her help with the English of the text.

\section{SUPPLEMENTARY MATERIAL}

The Supplementary Material for this article can be found online at: https://www.frontiersin.org/articles/10.3389/fpls.2019.00647/ full\#supplementary-material

Baruch, Z., and Goldstein, G. (1999). Leaf construction cost, nutrient concentration, and net CO 2 assimilation of native and invasive species in Hawaii. Oecologia 121, 183-192. doi: 10.1007/s00442005 0920

Bolpagni, R., Bresciani, M., Laini, A., Pinardi, M., Matta, E., Ampe, E. M., et al. (2014). Remote sensing of phytoplankton-macrophyte coexistence in shallow hypereutrophic fluvial lakes. Hydrobiologia 737, 67-76.

Bresciani, M., Rossini, M., Morabito, G., Matta, E., Pinardi, M., Cogliati, S., et al. (2013). Analysis of within-and between-day chlorophyll-a dynamics in 
mantua superior lake, with a continuous spectroradiometric measurement. Mar. Freshw. Res. 64, 303-316.

Callaway, R. M., and Aschehoug, E. T. (2000). Invasive plants versus their new and old neighbors: a mechanism for exotic invasion. Science 290, 521-523.

Colautti, R. I., Ricciardi, A., Grigorovich, I. A., and MacIsaac, H. J. (2004). Is invasion success explained by the enemy release hypothesis? Ecol. Lett. 7, 721-733. doi: 10.1111/j.1461-0248.2004.00616.x

Daehler, C. C. (2003). Performance comparisons of Co-Occurring native and alien invasive plants: implications for conservation and restoration. Annu. Rev. Ecol. Evol. Syst. 34, 183-211. doi: 10.1146/annurev.ecolsys.34.011802.132403

Dandelot, S., Verlaque, R., Dutartre, A., and Cazaubon, A. (2005). Ecological, dynamic and taxonomic problems due to Ludwigia (Onagraceae) in France. Hydrobiologia 551, 131-136.

D'Antonio, C. M., and Kark, S. (2002). Impacts and extent of biotic invasions in terrestrial ecosystems. Trends Ecol. Evol. 17, 202-204. doi: 10.1016/S01695347(02)02454-0

Davidson, A. M., Jennions, M., and Nicotra, A. B. (2011). Do invasive species show higher phenotypic plasticity than native species and, if so, is it adaptive? A meta-analysis. Ecol. Lett. 14, 419-431. doi: 10.1111/j.1461-0248.2011.01596.x

Davis, M. A., Grime, J. P., and Thompson, K. (2001). Fluctuating resources in plant communities: a general theory of invasibility. J. Ecol. 88, 528-534. doi: 10.1046/j.1365-2745.2000.00473.x

Díaz, S., Kattge, J., Cornelissen, J. H., Wright, I. J., Lavorel, S., Dray, S., et al. (2016). The global spectrum of plant form and function. Nature 529, 167-171. doi: 10.1038/nature16489

Dukes, J. S., and Mooney, H. A. (1999). Does global change increase the success of biological invaders? Trends Ecol. Evol. 14, 135-139. doi: 10.1016/S01695347(98)01554-7

Eilers, P. H. C., and Peeters, J. C. H. (1988). A model for the relationship between light intensity and the rate of photosynthesis in phytoplankton. Ecol. Model. 42, $199-215$.

EPPO (2004a). Data Sheet on Ludwigia peploides and L. uruguayensis (L. grandiflora). Available at: http://www.eppo.org/QUARANTINE/plants/ Ludwigia/LUDSS.html (accessed December 21, 2018).

EPPO (2004b). Nvasive Plants: Addition of Senecio Inaequidens and Two Ludwigia Species to the Eppo Alert List. Available at: https:/gd.eppo.int/taxon/SENIQ/ reporting (accessed December 21, 2018).

Fasoli, J. V. B., Mormul, R. P., Cunha, E. R., and Thomaz, S. M. (2018). Plasticity responses of an invasive macrophyte species to inorganic carbon availability and to the interaction with a native species. Hydrobiologia 817, 227-237. doi: 10.1007/s10750-018-3543-X

Feng, Y.-L., Lei, Y.-B., Wang, R.-F., Callaway, R. M., Valiente-Banuet, A., Li, Y.-P., et al. (2009). Evolutionary tradeoffs for nitrogen allocation to photosynthesis versus cell walls in an invasive plant. Proc. Natl. Acad. Sci. U.S.A. 106, 1853-1856. doi: 10.1073/pnas.0808434106

Filella, I., Porcar-Castell, A., Munné-Bosch, S., Bäck, J., Garbulsky, M., and Peñuelas, J. (2009). PRI assessment of long-term changes in carotenoids/chlorophyll ratio and short-term changes in de-epoxidation state of the xanthophyll cycle. Int. J. Remote Sens. 30, 4443-4455.

Funk, J. L., and Vitousek, P. M. (2007). Resource-use efficiency and plant invasion in low-resource systems. Nature 446, 1079-1081.

Gallardo, B., Clavero, M., Sánchez, M. I., and Vilà, M. (2016). Global ecological impacts of invasive species in aquatic ecosystems. Glob. Change Biol. 22, 151-163. doi: 10.1111/gcb.13004

Gamon, J., Kovalchuck, O., Wong, C., Harris, A., and Garrity, S. (2015). Monitoring seasonal and diurnal changes in photosynthetic pigments with automated PRI and NDVI sensors. Biogeosciences 12, 4149-4159.

Gamon, J. A., Peòuelas, J., and Field, C. B. (1992). A narrow-waveband spectral index that tracks diurnal changes in photosynthetic efficiency. Remote Sens. Environ. 41, 35-44.

Garbulsky, M. F., Peñuelas, J., Gamon, J., Inoue, Y., and Filella, I. (2011). The photochemical reflectance index (PRI) and the remote sensing of leaf, canopy and ecosystem radiation use efficiencies: a review and meta-analysis. Remote Sens. Environ. 115, 281-297.

Garrity, S. R., Eitel, J. U., and Vierling, L. A. (2011). Disentangling the relationships between plant pigments and the photochemical reflectance index reveals a new approach for remote estimation of carotenoid content. Remote Sens. Environ. $115,628-635$.
Genty, B., Briantais, J.-M., and Baker, N. R. (1989). The relationship between the quantum yield of photosynthetic electron transport and quenching of chlorophyll fluorescence. Biochim. Biophys. Acta Gen. Subj. 990, 87-92.

Gérard, J., Brion, N., and Triest, L. (2014). Effect of water column phosphorus reduction on competitive outcome and traits of Ludwigia grandiflora and L. peploides, invasive species in Europe. Aquat. Invasions 9, 157-166.

Gitelson, A. A., Gamon, J. A., and Solovchenko, A. (2017). Multiple drivers of seasonal change in PRI: implications for photosynthesis 1. Leaf level. Remote Sens. Environ. 191, 110-116.

Gitelson, A. A., Gritz, Y., and Merzlyak, M. N. (2003). Relationships between leaf chlorophyll content and spectral reflectance and algorithms for non-destructive chlorophyll assessment in higher plant leaves. J. Plant Physiol. 160, 271-282.

Gitelson, A. A., Merzlyak, M. N., and Chivkunova, O. B. (2001). Optical properties and nondestructive estimation of anthocyanin content in plant leaves. Photochem. Photobiol. 74, 38-45.

Hammer, Ø, Harper, D. A. T., and Ryan, P. D. (2001). Past: paleontological statistics software package for education and data analysis. Paleontol. Electrón. 4, 1-9.

Hernández-Clemente, R., Navarro-Cerrillo, R. M., Suárez, L., Morales, F., and Zarco-Tejada, P. J. (2011). Assessing structural effects on PRI for stress detection in conifer forests. Remote Sens. Environ. 115, 2360-2375.

Holmes, P. M., and Cowling, R. M. (1997). The effects of invasion by acacia saligna on the guild structure and regeneration capabilities of south african fynbos shrublands. J. Appl. Ecol. 34, 317-332.

Hufbauer, R. A., and Torchin, M. E. (2008). Integrating ecological and evolutionary theory of biological invasions. Biol. Invasions 193, 79-96. doi: 10.1086/658149

Hussner, A. (2009). Growth and photosynthesis of four invasive aquatic plant species in Europe. Weed Res. 49, 506-515.

Hussner, A., and Jahns, P. (2015). European native Myriophyllum spicatum showed a higher [Formula: see text] use capacity than alien invasive Myriophyllum heterophyllum. Hydrobiologia 746, 171-182. doi: 10.1007/s10750-014-1976-4

Hussner, A., van Dam, H., Vermaat, J. E., and Hilt, S. (2014). Comparison of native and neophytic aquatic macrophyte developments in a geothermally warmed river and thermally normal channels. Fundam. Appl. Limnol. 185, 155-165. doi: $10.1127 / \mathrm{fal} / 2014 / 0629$

Keane, R. M., and Crawley, M. J. (2002). Exotic plant invasions and the enemy release hypothesis. Trends Ecol. Evol. 17, 164-170. doi: 10.1016/S0169-5347(02) 02499-0

Lankau, R. A. (2011). Rapid evolutionary change and the coexistence of species. Annu. Rev. Ecol. Evol. Syst. 42, 335-354.

Leffler, A. J., James, J. J., Monaco, T. A., and Sheley, R. L. (2014). A new perspective on trait differences between native and invasive exotic plants. Ecology 95, 298-305.

Levine, J. M., and HilleRisLambers, J. (2009). The importance of niches for the maintenance of species diversity. Nature 461, 254-257. doi: 10.1038/ nature 08251

McKinney, M. L., and Lockwood, J. L. (1999). Biotic homogenization: a few winners replacing many losers in the next mass extinction. Trends Ecol. Evol. 14, 450-453.

Meyer, J.-Y., and Florence, J. (1996). Tahiti's native flora endangered by the invasion of Miconia calvescens DC.(Melastomataceae). J. Biogeogr. 23, 775-781.

Ming, R., VanBuren, R., Liu, Y., Yang, M., Han, Y., Li, L.-T., et al. (2013). Genome of the long-living sacred lotus (Nelumbo nucifera Gaertn.). Genome Biol. 14:R41. doi: $10.1186 /$ gb-2013-14-5-r41

Mitchell, C. E., and Power, A. G. (2003). Release of invasive plants from fungal and viral pathogens. Nature 421, 625-627.

Musil, C. F. (1993). Effect of invasive Australian acacias on the regeneration, growth and nutrient chemistry of South African lowland fynbos. J. Appl. Ecol. 30, 361-372.

Pinardi, M., Bartoli, M., Longhi, D., and Viaroli, P. (2011). Net autotrophy in a fluvial lake: the relative role of phytoplankton and floating-leaved macrophytes. Aquat. Sci. 73, 389-403.

Potu̇čková, M., Červená, L., Kupková, L., Lhotáková, Z., Lukeš, P., Hanuš, J., et al. (2016). Comparison of reflectance measurements acquired with a contact probe and an integration sphere: implications for the spectral properties of vegetation at a leaf level. Sensors 16:E1801.

Pyšek, P., and Richardson, D. M. (2007). "Traits associated with invasiveness in alien plants: where do we stand?," in Biological Invasions, ed. W. Nentwig (Berlin: Springer), 97-125. doi: 10.1007/978-3-540-36920-2_7 
R Development Core Team (2012). R: A Language and Environment for Statistical Computing. Vienna: R Foundation for Statistical Computing.

Rout, M. E., and Callaway, R. M. (2009). An invasive plant paradox. Science 324, 734-735.

Sims, D. A., and Gamon, J. A. (2002). Relationships between leaf pigment content and spectral reflectance across a wide range of species, leaf structures and developmental stages. Remote Sens. Environ. 81, 337-354.

Stratoulias, D., Balzter, H., Zlinszky, A., and Tóth, V. R. (2015). Assessment of ecophysiology of lake shore reed vegetation based on chlorophyll fluorescence, field spectroscopy and hyperspectral airborne imagery. Remote Sens. Environ. 157, 72-84. doi: 10.1016/j.rse.2014.05.021

Thouvenot, L., Haury, J., and Thiébaut, G. (2013). Seasonal plasticity of Ludwigia grandiflora under light and water depth gradients: an outdoor mesocosm experiment. Flora Morphol. Distrib. Funct. Ecol. Plants 208, 430-437.

Van Kleunen, M., Weber, E., and Fischer, M. (2010). A meta-analysis of trait differences between invasive and non-invasive plant species. Ecol. Lett. 13, 235-245.

Vilà, M., Espinar, J. L., Hejda, M., Hulme, P. E., Jarošík, V., Maron, J. L., et al. (2011). Ecological impacts of invasive alien plants: a meta-analysis of their effects on species, communities and ecosystems. Ecol. Lett. 14, 702-708. doi: 10.1111/j.1461-0248.2011.01628.x

Villa, P., Bresciani, M., Bolpagni, R., Pinardi, M., and Giardino, C. (2015). A rulebased approach for mapping macrophyte communities using multi-temporal aquatic vegetation indices. Remote Sens. Environ. 171, 218-233.

Villa, P., Pinardi, M., Bolpagni, R., Gillier, J.-M., Zinke, P., Nedelcut, F., et al. (2018). Assessing macrophyte seasonal dynamics using dense time series of medium resolution satellite data. Remote Sens. Environ. 216, 230-244.

Villa, P., Pinardi, M., Tóth, V. R., Hunter, P. D., Bolpagni, R., and Bresciani, M. (2017). Remote sensing of macrophyte morphological traits: implications for the management of shallow lakes. J. Limnol. 76, 109-126. doi: 10.4081/jlimnol. 2017.1629

Vitousek, P. M. (1986). "Biological invasions and ecosystem properties: can species make a difference," in Ecology of Biological Invasions of North America and Hawaii. eds H. A. Mooney and D. A. James (New York, NY: Springer).

Vitousek, P. M. (1990). Biological invasions and ecosystem processes: towards an integration of population biology and ecosystem studies. Oikos 57, 7-13. doi: $10.2307 / 3565731$

Wellburn, A. R. (1994). The spectral determination of chlorophylls a and b, as well as total carotenoids, using various solvents with spectrophotometers of different resolution. J. Plant Physiol. 144, 307-313.

Wolkovich, E. M., and Cleland, E. E. (2011). The phenology of plant invasions: a community ecology perspective. Front. Ecol. Environ. 9, 287-294.

Wu, C., Niu, Z., Tang, Q., and Huang, W. (2010). Revised photochemical reflectance index (PRI) for predicting light use efficiency of wheat in a growth cycle: validation and comparison. Int. J. Remote Sens. 31, 2911-2924.

Zhou, L., and Zhou, G. (2009). Measurement and modelling of evapotranspiration over a reed (Phragmites australis) marsh in Northeast China. J. Hydrol. 372, $41-47$.

Conflict of Interest Statement: The authors declare that the research was conducted in the absence of any commercial or financial relationships that could be construed as a potential conflict of interest.

Copyright (c) 2019 Tóth, Villa, Pinardi and Bresciani. This is an open-access article distributed under the terms of the Creative Commons Attribution License (CC BY). The use, distribution or reproduction in other forums is permitted, provided the original author(s) and the copyright owner(s) are credited and that the original publication in this journal is cited, in accordance with accepted academic practice. No use, distribution or reproduction is permitted which does not comply with these terms. 